\title{
A (DES)CONSTRUÇÃO DO DIREITO ATRAVÉS DO HABITAR POÉTICO ANTI SISTÊMICO: REFLEXÕES ENTRE KELSEN, HEIDEGGER E LISPECTOR
}

\section{Débora Caetano Dahas ${ }^{1}$}

Resumo: O presente artigo visa investigar a aplicabilidade da teoria de Martin Heidegger na Filosofia do Direito. Dessa forma, busca responder (de forma preliminar e não esgotável) a seguinte questão: seria necessária a operação de uma desconstrução sistêmica anti sistêmica do Direito para que então fosse realizada a construção de um devir Direito baseado em uma ética do cuidado heideggeriana? O tema é extenso e demasiadamente complexo, mas o estudo aqui proposto visa ser um ponto de partida para a reflexão da utilização da hermenêutica de Heidegger e das suas possíveis consequências para a prática jurídica.

Palavras-chave: Hermenêutica Jurídica; Clarice Lispector; Hans Kelsen; Martin Heidegger; Direito e Literatura;

\section{THE DECONSTRUCTION OF LAW THROUGH AN ANTI SYSTEMIC AND POETIC INHABITING: REFLECTIONS ON KELSEN, HEIDEGGER AND LISPECTOR}

\begin{abstract}
This article aims to investigate the applicability of Martin Heidegger's theory in Legal Philosophy. Thus, it seeks to answer (in a preliminary and inexhaustible way) the following question: would it be necessary to operate an anti-systemic deconstruction of law so that the construction of a becoming law based on a Heideggerian ethics would then be carried out? The theme is indeed extensive and too complex, but the study proposed here aims to be a starting point for a reflecting on the use of Heidegger's hermeneutics and its possible consequences for legal practice.
\end{abstract}

Keywords: Legal Hermeneutics; Clarice Lispector; Hans Kelsen; Martin Heidegger; Law and Literature;

\section{INTRODUÇÃO}

No presente artigo, me proponho a investigar em que medida a hermenêutica desenvolvida através da teoria fenomenológica de Martin Heidegger pode servir como engrenagem para o movimento de construção - que mais tarde neste mesmo texto será conectada à ideia de desconstrução em Heidegger - de um Direito que seja visto como fenômeno humano (e não precisamente social) baseado no que podemos chamar de Ética do Cuidado.

\footnotetext{
${ }^{1}$ Escritora, poetisa, professora e advogada. Doutoranda em Teoria do Direito pela Pontifícia Universidade Católica de Minas Gerais. Pesquisadora visitante na Universität Salzburg com bolsa CAPES/PDSE. Mestre e especialista em Direito Empresarial pela Faculdade de Direito Milton Campos. Bacharel em Direito pela Universidade de Uberaba. Email: debora.dahas@hotmail.com.
} 
Martin Heidegger foi - quiçá - o filósofo de língua germânica mais importante do século XX. Suas incursões filosóficas se encontram em vários livros e artigos publicados em diversos países e traduzidos para diversos idiomas. A importância de sua obra é tão inegável quanto às controvérsias que cercam sua vida (por óbvio, falo aqui em especial de sua filiação ao Partido Social-Nacionalista alemão). Dada a vastidão e a complexidade de seus escritos, irei me ater aqui ao estudo de seletas obras. Os trabalhos de Heidegger por mim escolhidos são: o seminal Ser e tempo, publicado em 1927, a conferência “...Poeticamente o Homem Habita...” e o livro A Caminho da Linguagem, publicado originalmente em 1959.

Como as ponderações de Heidegger passam inevitavelmente pela literatura e pela arte, irei me valer nas linhas que se seguem de uma investigação não engessada. Utilizarei o conto "Amor" de Clarice Lispector como ponto de referência para as reflexões que a seguir se desenvolverão sobre os desdobramentos da hermenêutica da vivência no mundo. A ideia primordial é habitar poeticamente o próprio pensar, através de uma conexão (necessária, portanto não contingente) entre filosofia e literatura.

Posteriormente, escolho como ponto de referência para pensar o Direito o conceito positivista de Hans Kelsen. O filósofo austríaco é um dos grandes nomes da Teoria do Direito e seus esforços no sentido de desenvolver uma teoria geral e científica dentro dos estudos jurídicos são de suma importância para as construções jus-teóricas do século XX. Aqui, então, vale lembrar que a primeira edição de seu emblemático trabalho Teoria Pura do Direito, lançada em 1934, é mais curta e pontual do que a segunda. A publicação da segunda edição da Teoria Pura do Direito, em 1960, traz em si um Kelsen mais maduro. Nela encontramos a resposta de Kelsen a várias críticas a respeito de seu trabalho, bem como o esboço de uma Teoria da Discricionariedade ${ }^{2}$. A segunda edição é, assim, a obra mais representativa do pensamento do autor e, por isso, foi escolhida como contraponto para análise crítica aqui realizada.

A partir daí passarei a discorrer sobre a inevitável desconstrução do Direito, se visto sob uma ótica fenomenológica, colocando em posições conflitantes a ontologia heideggeriana e a Teoria do Direito cientificista de Kelsen.

\section{HEIDEGGER E DASEIN, CLARICE E O CEGO}

\footnotetext{
${ }^{2}$ Não há consenso teórico sobre a existência de uma Teoria da Discricionariedade na obra de Hans Kelsen. Para mais detalhes sobre o tema, vide os trabalhos de Alexandre Travessoni Gomes Trivisonno e Stanley L. Paulson.
} 
Para as reflexões que se seguirão sobre o Direito e o habitar poético é necessário que sejam realizadas algumas considerações prévias sobre a filosofia de Heidegger. Não pretendo com o resumo que farei adiante, tratar sobre todos os pontos importantes daquilo que o filósofo desenvolveu. Irei me ater, então, a algumas ideias principais relevantes ao estudo aqui proposto. Dessa forma, inicio as considerações sobre a filosofia fenomenológica em Heidegger me valendo das palavras de Marco Aurélio Fernandes, que explica que,

\begin{abstract}
Denominamos de "ôntico" o que concerne ao ente, ou seja, ao que é, ao sendo. Denominamos de "ontológico" o que concerne ao ser. Esta distinção pressupõe, pois, uma diferença, não entre ente e ente, mas entre ente e ser. Como, porém, esta diferença entre ente e ser é uma diferença de ser e não uma diferença entre entes ou entre aspectos dos entes, não sendo, portanto, uma diferença ôntica, então a denominamos "diferença ontológica". Nesta colocação, porém, está pressuposto que, se vigora uma diferença, vige também uma referência entre ente e ser. Pois, como poderia haver uma diferença sem referência mútua? Ente e ser se diferenciam à medida que se referenciam um ao outro. Contudo, também esta referência não é ôntica, isto é, uma referência entre ente e ente ou entre aspectos do ente, mas uma referência de ser entre ente e ser, portanto, uma referência ontológica. A questão é: como fica essa colocação para quem só tem olhos para o ôntico? Resposta: não fica, supondo-se que haja alguém assim. Mas, há alguém assim? A resposta, neste caso, parece ambígua: por um lado, todos somos de alguma maneira cegos para o ontológico; por outro, todos, por natureza, temos a capacidade de vê-lo. Com efeito, nós já sempre o vimos, mas não nos atinamos para essa visão. Nós já partimos sempre de uma apreensão do ente enquanto ente, e isto quer dizer, do ente no seu ser. (FERNANDES, 2011, pp. 158-159)
\end{abstract}

Nesse sentido, o filósofo da Floresta Negra, em seus esforços de investigação, procurou desvelar - através do fenomenológico - a essência do Ser para além do ente. Dessa forma, para Heidegger, nascemos e somos lançados para o mundo. Somos portanto Dasein - palavra em alemão que pode ser traduzida literalmente como ser-aí, em português, e também como "presença" - repletos de possibilidade. Podemos dizer, em linhas gerais, que Dasein é a manifestação no mundo do Ser (em alemão designado pelo verbo Sein). O Dasein, por sua vez, é o Ser ontológico. O Ser não se explica, diferentemente dos entes que, por sua vez, podem ser conceituados e parametrizados. Isso, pois, Sein é anterior; é ontológico, não ôntico. Enquanto as explicações sobre o ente se esgotam, o Sein tem natureza própria e suas explicações consequentemente não se esgotam da mesma maneira. Ainda sobre o tema, Marco Aurélio Fernandes resume elucidamente:

Dito de outro modo: nós nos movemos já sempre numa compreensão do ser, embora esta compreensão seja, de início e na maior parte das vezes, não temática, não 
explícita, não teórica, mas antes "operativa", que se dá com e no nosso próprio ser, com e no nosso próprio existir, em-sendo, em existindo (Heidegger, 1988, p. 29). Em todo o lidar com o ente nós já sempre o apreendemos como ente simplesmente e, ademais, como ente deste ou daquele ser: o instrumento na sua instrumentalidade, o vivente no vigor da vida, o homem no modo de ser de sua humanidade, etc. Emsendo, nós mesmos já sempre nos abrimos para o ser, a priori, nós já sempre mantemos uma relação de ser com o que somos e com o que não somos, com o que podemos ser e com o que devemos ser, com o que vamos nos tornando, enfim, com nossas possibilidades e impossibilidades de ser. Esta abertura se dá numa compreensão, que é anterior a toda tematização, que é ela mesma e nela mesma um poder-ser. (FERNANDES, 2011, pp. 159)

O competente resumo apresentado alhures versa sobre temas tratados por Heidegger em Ser e Tempo, obra mais importante de sua carreira filosófica. É nela que se inaugura a segunda fase do pensamento do autor, que passa a mostrar a imersão do $\operatorname{Dasein}^{3}$ (que podemos chamar de ser-aí ou de presença) em si mesmo de modo transcendental como elemento central de sua filosofia. Assim, Heidegger inicia em seu trabalho um processo de revisão, se voltando para o fenômeno da história do esquecimento do ser como ponto inicial para suas indagações. Heidegger faz menção ao Seyn (com Y, no alemão arcaico) como dimensão pré-predicativa (HEIDEGGER, 2015), que vai além daquele plano em que alguns filósofos que o precederam - como, por exemplo, Tomás de Aquino e Santo Agostinho - colocaram o ser. Heidegger passa da visão ôntica da investigação sobre o ser - “o que é?” - para uma investigação ontológica - “como é ser?".

Com a finalidade de ilustrar o que será explorado adiante, ressalto que em suas reflexões Heidegger diz que ao nascermos somos lançados no mundo (Geworfenheit). Entendemos esse mundo que nos circunda a partir das relações com os seres e os entes que estão à nossa volta. Heidegger ressalva, porém, que ao sermos lançados no mundo caímos em algo que o autor chama de falatório (das Gerede). Esse falatório se constitui na utilização vazia da linguagem, nas conversas que ocupam o tempo de forma impessoal. Vivemos, então, na impessoalidade. Nos coisificamos em um mundo de obrigações e de falatório. Passamos, assim, a viver de forma inautêntica (Ungentlichkeit).

Além disso, é preciso destacar que a morte é o fim inevitável do Dasein. Devemos, então, aceitar a nossa própria finitude. Em um horizonte de temporalidade, estamos abertos a essas diversas possibilidades. Nesse sentido, um dos passos mais importantes para o mergulho

\footnotetext{
${ }^{3}$ A edição de Ser e Tempo utilizada como fonte dos estudos presentes neste artigo - publicada pela editora Vozes tem uma peculiaridade: nesta tradução Dasein foi traduzida para "presença". Optei, porém, pela utilização do termo Dasein no idioma original, em alemão. Vale ressaltar que, comumente, a expressão Dasein é traduzida de forma literal como ser-aí.
} 
na essência é justamente a aceitação de nossa própria finitude. Contudo, a ignorância em relação à finitude do ser nos impede de entrar em contato com aquilo que é o ontológico do Ser. Isso tudo resulta no esquecimento do Ser, ou na coisificação do Ser, ou seja, em transformação em uma vida irrefletida.

Há uma mundanidade que cria efeitos sobre o Ser ao sermos lançados no mundo dentro desse falatório. A pessoa é constituída dentro de uma realidade na qual ela se insere, e deve ser levada a pensar dentro daquele jogo de linguagem. Para que possamos compreender ou acessar algo que é da essência do Dasein - já que não é possível esgotar as possibilidades daquilo que é a essência do Ser - precisamos superar essas barreiras que nos são impostas. Inevitavelmente, a compreensão da finitude - em um movimento de transcendência - é fundamento de uma certa existência predicativa do Dasein. Em notas introdutórias sobre a tradução do termo Dasein, Márcia Sá Cavalcante Schubak esclarece que,

Transcendência é, para Heidegger, o modo em que "Dasein" existe, a saber, finitamente. "Dasein" existe finitamente, o que significa ex-centricamente, sendo em si mesmo para além de si mesmo, superando a si num antecipar-se a si. Transcendência da existência significa infinição, o que Heidegger define como estrutura da "cura", como estrutura de anteceder a si mesma já sendo em... junto a... o mundo. (SCHUBAK, 2015, p. 18)

A filosofia de Heidegger é, então, ação. Ação essa que se faz na tra-dução, quero dizer, na "condução para além de si, ser em si outro" (SCHUBAK, 2015, p. 19) Os entes só são visíveis, de acordo com Heidegger, porque o Dasein - o ser humano - é aberto. A abertura é possibilidade, assim, de fazer com que os entes sejam. O Ser existe porque está aberto para tudo aquilo que é diferente de si. Assim, o Ser é ser-no-mundo (in der Weld sein).

O revolver para um vida autêntica (Eigentlichkeit) é crucial para que possamos entrar em contato com a essência do Ser. Esse revolver que abre - ou descerra - o Dasein para o contato com a essência passa, necessariamente, pela disposição (Befindlichkeit) de afectos e sentimentos, e pela compreensão (Verständnis). Outro passo para a abertura para a essência é a linguagem. Isso, pois,

A linguagem pertence, em todo caso, à vizinhança mais próxima do humano. A linguagem encontra-se por toda parte. Não é, portanto, de admirar que, tão logo o homem faça uma idéia do que se acha ao seu redor, ele encontre imediatamente também a linguagem, de maneira a determiná-la numa perspectiva condizente com o que a partir dela se mostra. O pensamento busca elaborar uma representação universal da linguagem. $\mathrm{O}$ universal, o que vale para toda e qualquer coisa, chama-se essência. 
Prevalece a opinião de que o traço fundamental do pensamento é representar de maneira universal o que possui validade universal. (HEIDEGGER, 2012a, p. 7)

Acrescento aqui que, em termos heideggerianos, a linguagem encontra sua melhor forma na arte. Dentre as manifestações artísticas, a poesia ${ }^{4}$ é - por excelência - o lugar em que a linguagem se dá em sua mais pura e essencial maneira. Assim, podemos dizer que o viver poético é o viver que permite de melhor forma o contato com a essência do Ser. A vivência aberta à linguagem - ou seja, a vivência que se dá em poesia - é a que nos possibilita essa abertura à essência do Ser. Através do habitar poético no mundo reformulamos de modo contínuo aquilo que somos e, em nossa finitude, experienciamos aquilo que há de ontológico e que nos antecede. Ora, diferentemente dos entes - que apenas são - o ser humano é existência (é, existindo). É então afetado, ou seja, tocado pelos afectos ${ }^{5}$ que o circundam e que perpassam aquilo que é a sua experiência.

Faço aqui uma pausa e explico que não podemos falar em uma possível abertura que a linguagem (poética) enseja - ou percorrer o caminho que da linguagem - sem presumirmos que aquele à quem falamos seja um leitor. Não-leitores muito provavelmente não entenderão. Permito-me, então, a liberdade de não me ater à uma descrição do conteúdo do conto de Clarice Lispector no qual baseamos a reflexão que se segue. Presumo que o leitor que tem em mãos o presente trabalho já o tenha lido. Em caso negativo, peço que pare a leitura deste texto, leia Clarice $^{6}$, e volte mais tarde. Adiante, irei discorrer sobre "Amor"7 como se o meu leitor fosse também leitor de Clarice.

Uso Clarice aqui, pois, apesar de não ser poeta no sentido coloquial que carrega a palavra poeta, é sabido que a escrita de Clarice é poética em seu cerne. Se para Heidegger "a

\footnotetext{
${ }^{4}$ Nesse sentido, digo - em síntese - que "A busca pela essência daquilo que é o Ser é, então, questão central à filosofia. Mas não é simples. O Ser escapa, (porque) é infinito - ao contrário de nós. Dessa forma, para entrar em contato com o verdadeiro Ser é preciso que haja um momento de abertura. Essa abertura em termos heideggerianos se dá através da arte, que se manifesta pela linguagem. Essa - a linguagem - vem à tona, porém, quando menos se espera. É na falta dela, dizia Heidegger, que ela está. Quando não se encontram as palavras, a abertura à linguagem acontece, e a essência do Ser se mostra. Na ausência, portanto, há a existência. Então, a melhor forma de se encontrar o Ser por meio da arte (que se manifesta através da linguagem), para Heidegger, é a poesia." (DAHAS, 2019, p. 14)

${ }^{5}$ Escolho aqui a grafia afecto e não afeto - ora tradução da palavra em latim affectus -, pois me remeto neste momento à ideia de afecto na filosofia de Baruch de Spinoza. Para mais sobre o tema, vide as obras "Ética" escrita por Baruch de Spinoza, bem como "Spinoza: filosofia prática", de autoria de Gilles Deleuze.

${ }^{6}$ No corpo do texto chamo-a de Clarice, e não de Lispector, por uma questão simples: seu primeiro nome carrega em si o significado daquilo que de mais puro há na literatura. Existe - nesse "Clarice" - uma força hermética e indomável, pois sabemos de quem é o nome, e sabemos o que ele significa para a Literatura. Por uma questão de respeito e reverência, me refiro a ela como Clarice, pois isso basta.

${ }^{7}$ Conto publicado originalmente na obra Laços de Família, de 1960.
} 
poesia não sobrevoa e nem se eleva sobre a terra a fim de abandoná-la e pairar sobre ela. É a poesia que traz o homem para a terra, para ela, e assim o traz para um habitar" (HEIDEGGER, 2012b, p. 169), posso dizer com certa tranquilidade que Clarice habitou em poesia.

Agora, "Amor".

Ana - a personagem que move o conto de Clarice - anda pelo seu mundo (o mundo de todos, mas que através de sua percepção é também o mundo dela) e faz aquilo que tem que fazer. Anda, compra, bebe, come... vê. No exercício de ver se depara com aquilo que é escuridão: um cego - em movimento repetitivo preso na penumbra daquele que enxerga mas não pode ver - masca um chiclete. Com o freio brusco do bonde, Ana derruba a sacola, e os ovos que lá estavam (à salvo) se quebram com o impacto da realidade que é a casca de ovo no chão duro. A realidade do cego que enxerga sem ver e da Ana que vê mas não enxerga é como a realidade que quebra os ovos. Opera-se ali uma desconstrução: o que era antes já não é mais e dá lugar a um ser outro. Os ovos quebrados são, metaforicamente, a desconstrução da escuridão e a construção de um novo olhar. Ana agora enxerga e vê. Anda pelas ruas, pelo jardim botânico carioca, e repara por lá coisas que antes apenas via e não enxergava. Passa a habitar o mundo que habita, poeticamente. E, ao habitar, apreende e compreende. Vale ressaltar que,

\footnotetext{
Compreensão não significa, aqui, conhecimento objetivo ou objetivante e nem mesmo conhecimento subjetivo ou reflexivo. Caso convenha falar de conhecimento, então há que se dizer que a compreensão é um conhecimento em-sendo, em existindo, um conascimento ou uma co-nascença com as possibilidades da existência. Compreender é, aqui, saber de si, saber como se vai, a quantas anda o si-mesmo. Trata-se de um conhecimento que é anterior a todo o reconhecimento. Trata-se de um saber que é sabor de experiência feita. Compreender é, aqui, existir. Isto significa: ser lançando-se para um poder-ser. (FERNANDES, 2011, p. 166)
}

Mas a que/quem isso tudo interessa?

Interessa a todos nós, que pretendemos enxergar algo em uma possível relação entre a hermenêutica de Heidegger e no Direito. O movimento poiético, repetitivo e padronizado, do cego que masca o chiclete no escuro de si mesmo não é diferente do movimento repetitivo do viver de Ana, que vive na mesma escuridão metafórica do cego, presa em suas concepções e conceitos pré-determinados e determinantes do que pode e deve se fazer. O momento em que ela vê o cego é o momento do espanto, tão caro à filosofia e à arte de pensar. Pois é o espantar que permite a inserção no nosso mundo de algo que a ele é transcendental. A hermenêutica como forma de aproximação que é - se materializa nesse momento de espanto, que permite um encontro com algo alheio que provoca. 
O compreender se dá a partir desse espanto. O Dasein, antes preso na banalidade do cotidiano mundano e do falatório, encontra na abertura da linguagem a passagem da inautenticidade para a autenticidade. É preciso então que tenhamos uma experiência com a linguagem. Sobre essa experiência, Heidegger diz

\footnotetext{
Fazer uma experiência com a linguagem significa portanto: deixarmo-nos tocar propriamente pela reivindicação da linguagem, a ela nos entregando e com ela nos harmonizando. Se é verdade que o homem, quer o saiba ou não, encontra na linguagem a morada própria de sua presença, então uma experiência que façamos com a linguagem haverá de nos tocar na articulação mais íntima de nossa presença. Nós, nós que falamos a linguagem, podemos nos transformar com essas experiências, da noite para o dia ou com o tempo. (HEIDEGGER, 2012a, p. 121)
}

Através dessa abertura, é possível se deparar com a Verdade do Ser, e encontrar assim o Ser que não é apenas ser-aí. Assim, está presente - e é pre-sença - então.

\section{O SISTEMA}

Na Filosofia do Direito, como bem sabemos, existem diversas questões já debatidas há tempos. Questões essas que retornam com mais ou menos força ao longo dos séculos. A natureza da autoridade, a validade das normas, e a relação necessária ou contingente entre Direito e Moral são alguns desses tópicos. Vários são os pensadores que se debruçam de maneira detida ou abrangente sobre esses problemas. Poucos foram tão relevantes quanto Hans Kelsen. Ao me propor a discutir a (des)construção do Direito, elejo a Teoria Pura de Kelsen como o meu objeto de estudo.

Na segunda edição da Teoria Pura do Direito encontramos um precioso refinamento das ideias de Kelsen sobre a pureza do Direito como ciência. Dizer que o Direito é uma ciência pura é colocá-lo em um locus epistemológico independente. Não se depende diretamente mais - diretamente ou necessariamente - de estudos diversos (sociológicos ou antropológicos, por exemplo) para apreender e compreender o Direito como o fenômeno que é.

Nesse sentido, a filosofia do Direito de Kelsen pode ser brevemente explicada da seguinte forma: o filósofo austríaco buscou, com seus esforços, desenvolver uma teoria geral do Direito que o coloca-se em posição científica de pureza. Isso quer dizer, em linhas gerais, que o estudo do Direito deveria ser independente de quaisquer outras ciências. Para Kelsen, a teoria pura "quer única e exclusivamente conhecer o seu próprio objeto [...] é ciência jurídica e 
não política do Direito" (KELSEN, 2009, p. 1). Para Kelsen - considerado o maior expoente do positivismo jurídico ${ }^{8}-$

[...] o Direito, que constitui o objeto deste conhecimento, é uma ordem normativa da conduta humana, ou seja, um sistema de normas que regulam o comportamento humano. Com o termo "norma" se quer significar que algo deve ser ou acontecer, especialmente que um homem se deve conduzir de determinada maneira. (KELSEN, 2009, p. 5)

O sistema jurídico é, então, uma ordem. Se, de acordo com Kelsen, uma ordem "é um sistema de normas cuja unidade é constituída pelo fato de todas elas terem o mesmo fundamento de validade" (KELSEN, 2009, p 33), deve-se estabelecer - como consequência imediata - qual o fundamento do Direito. O fundamento, para o autor, se encontra no que ele denomina de Grundnorm ou norma fundamental. Essa norma é fundamental pois é o pressuposto da validade do Direito.

Explico que a norma fundamental serve de solução para o seguinte problema: quando o jurista busca a validade de uma regra específica do Direito ele se remete a uma outra regra que a autoriza. Assim, uma regra específica do Código Penal Brasileiro é válida se estiver de acordo com a regra superior que a autoriza. Para ser válida, portanto, ela deve estar de acordo com a regra que versa sobre quem tem autoridade para legislar sobre Direito Penal. Esse regresso seria infinito e interminável caso não houvesse uma norma suprema segundo a qual todas as outras devem estar de acordo. Assim, a norma fundamental é a norma que autoriza todo o sistema jurídico e lhe dá, finalmente, validade. A Grundnorm de Kelsen é uma norma pressuposta que faz com que interpretemos um ato como criador de normas objetivamente válidas (KELSEN, 2015). Em outras palavras, ela é

aquela norma que é pressuposta quando o costume, através do qual a Constituição surgiu, ou quando o ato constituinte (produtor da Constituição) posto conscientemente por determinados indivíduos são objetivamente interpretados como fatos produtores de normas. [...] A norma fundamental é a instauração do fato fundamental da criação jurídica e pode, nestes termos, ser designada como constituição no

\footnotetext{
${ }^{8}$ Alexandre T. G. Trivisonno, em seus estudos sobre Robert Alexy, destaca que o autor classifica as Teorias do Direito de acordo com entendimento dessas em relação à conexão conceitual entre direito e moral. Na classificação de Alexy encontram-se as seguintes categorias: a) positivismo inclusivo; b) positivismo exclusivo; c) não-positivismo inclusivo; d) não-positivismo inclusivo; e) não-positivismo sub inclusivo (TRIVISONNO, 2015). Os positivistas, em linhas gerais, defendem que não há relação conceitual necessária entre Direito e Moral. Os não-positivistas são contrários a essa ideia e argumentam que a Moral faz parte do conceito de Direito.
} 
sentido lógico-jurídico, para a distinguir da Constituição em sentido jurídico-positivo. (KELSEN, 2009, pp. 221-222)

Ademais, Kelsen observa que ao desenvolver a ideia da Grundnorm o que foi realizado não passou de uma esquematização filosófica de algo que já acontece inegavelmente na prática jurídica, já que essa "é somente o resultado de uma análise do processo que o conhecimento jurídico positivista desde sempre tem utilizado" (KELSEN, 2009, p. 228). Convencionalmente, os juristas pressupõem a existência de uma norma superior às outras normas e que, portanto, lhes confere validade. O raciocínio da aplicação do Direito seria: devo obedecer a lei X, pois ela está de acordo com a lei autorizadora Y; a lei autorizadora Y é válida pois está de acordo com a Constituição (no sentido jurídico-positivo); deve-se obedecer a Constituição (no sentido lógico-jurídico, sendo este o enunciado através do qual se identifica a Grundnorm). O escalonamento das normas para a verificação de sua validade é, para Kelsen, empiricamente verificável. Cabe dizer também que “quando o Direito é aplicado por um órgão jurídico, este necessita de fixar o sentido das normas que vai aplicar, tem de interpretar as normas" (KELSEN, 2009, p. 387).

Vale ressaltar que, para Kelsen, as normas estão no campo do ser - $\operatorname{Sein}^{9}$, em alemão - enquanto o valor está no campo do dever ser - Sollen, também em alemão. A ciência do Direito se preocupa, portanto, não com a questão meramente valorativa. O que o direito deve ser não importa aos estudiosos. O que importa é aquilo que o Direito é.

Nesse sentido, o autor completa que apesar de Direito e Moral serem ordens sociais que têm a mesma fonte, estas não se confundem. A moral não goza da possibilidade de utilização da coerção para se fazer cumprir. A coerção para cumprimento da moral não se encontra em um campo institucionalizado e sistematizado, como é o caso do Direito. Esse se diferencia daquele como ordem social pois há o monopólio da coerção de forma institucional para se fazer valer aquilo que é a norma posta. Dessa forma, pode-se até argumentar no sentido de que há uma relação entre Direito e Moral, mas essa relação - para os positivistas como Kelsen - não é conceitualmente necessária.

Tudo isso significa dizer que Kelsen entende o Direito como sistema de normas coercitivas, pois prescrevem condutas e atrelam ao não cumprimento dessa conduta uma sanção. A autoridade tem, portanto, o monopólio do uso da violência que se dá através do

\footnotetext{
${ }^{9}$ A palavra Sein em língua alemã corresponde, em tradução literal, ao verbo "ser" em português. Como conceito filosófico, porém, assume sentidos distintos nos trabalhos de Martin Heidegger e Hans Kelsen.
} 
Estado como forma de se fazer cumprir as normas. Para o filósofo, "as ordens sociais a que chamamos Direito são ordens coativas da conduta humana" (KELSEN, 2009, p. 36) já que aplicam um mal através de uma coerção. Exerce, então, a regulação de conduta de modo positivo e negativo, proibindo ou permitindo que determinados atos sejam praticados.

Por fim, vale ressaltar que o Direito como sistema de normas coativas se coloca como moldura dentro da qual o juiz exerce a atividade decisional. Não há, então, uma única resposta correta. Dentro da moldura posta pelo Direito é possível - por meio de uma atividade interpretativa - se encontrar a melhor resposta para o caso concreto naquele momento. Nesse sentido, as decisões judiciais também impõem normas a serem cumpridas. Aquilo que se coloca nas decisões judiciais constitui norma jurídica individual, já que é "posto como devido (devendo-ser) por uma norma que se apresenta sob a forma de sentença judicial” (KELSEN, 2009, p. 222). Sobre o exercício interpretativo das normas no momento de aplicação do Direito, Kelsen ainda alerta que

\begin{abstract}
A interpretação jurídico-científica não pode fazer outra coisa senão estabelecer as possíveis significações de uma norma jurídica. Como conhecimento do seu objeto, ela não pode tomar qualquer decisão entre as possibilidade por si mesma reveladas, mas tem de deixar tal decisão ao órgão que, segundo a ordem jurídica, é competente para aplicar o Direito. [...] A interpretação jurídico-científica tem de evitar, com o máximo cuidado, a ficção de que uma norma jurídica apenas permite, sempre e em todos os casos, uma só interpretação: a interpretação "correta". (KELSEN, 2009, p. 396)
\end{abstract}

Dessa forma, podemos verificar no trabalho de Kelsen as três mais importantes teses do positivismo jurídico: a tese do pedigree (a validade das normas individuais depende de sua adequação a uma norma superior que fundamenta todo o sistema jurídico), a tese dos fatos sociais (segunda a qual a norma que fundamental o sistema jurídico advém de fatos sociais, ou seja, de convenções aceitas pelos sujeitos que fazem parte daquele sistema jurídico do ponto de vista do participante) e a tese da separação (que versa que não há relação conceitual entre Direito e Moral).

Se em Hans Kelsen encontramos a mais completa e bem sucedida tentativa de colocar o Direito no campo da ciência pura, através de Heidegger podemos falar também em uma tentativa - que talvez também seja igualmente bem sucedida - de trazer o Direito para o campo ontológico daquilo que ele é e deve ser em sentido não-ôntico e interconectado. 
Realizadas as devidas observações sobre a fenomenologia heideggeriana e a ideia de sistema jurídico em Kelsen, devo prosseguir para a crítica ao sistema jurídico a partir de um ponto de vista hermenêutico.

\title{
4. A (DES)CONSTRUÇÃO
}

Uma vez estabelecido o conceito de Direito nos termos kelsenianos e realizadas as devidas considerações sobre a hermenêutica heideggeriana, resta a seguinte questão: seria necessária a operação de uma desconstrução sistêmica anti sistêmica do Direito para que então fosse realizada a construção de um devir Direito baseado na ética do cuidado heideggeriana?

Neste momento, uma curta digressão se faz imperiosa. Cuidado - ou Sorge ${ }^{10}$, em alemão - em Heidegger é algo não-ôntico, mas sim hermeneuticamente ontológico. A ética do cuidado tem como base, portanto, a ideia anunciada por Heidegger de que

\begin{abstract}
[...] quando pensamos sobre o sentido de nosso ser, nós nos colocamos diante do caminho que devemos trilhar enquanto um ser que, na medida em que está sendo, põe em jogo sua própria existência. Ao trilharmos este caminho também nos encaramos a nós mesmos, e, assim, diante de um relacionamento intrínseco conosco mesmo. Para Heidegger, só podemos nos antecipar porque já sempre e a cada vez estamos em um mundo, ou seja, estamos referenciados a um contexto de significância em que o que acontece nos faz sentido (Cf. Heidegger, 2001, p. 54). Todavia, não estamos sós no mundo, também estamos sempre junto às coisas e às pessoas que vêm ao nosso encontro enquanto existimos. Junto às coisas e às pessoas o cuidado pode ser compreendido como ocupação ou preocupação. A todo este contexto ontológicoexistencial Heidegger denomina cuidado. (SANTOS, 2011, p. 40)
\end{abstract}

O cuidado como a priori fundamental (SANTOS, 2011) é o ponto de partida para se pensar uma ética fenomenológica. Cuidar o outro é ser o melhor outro para o outro. Cuidar é primordial pois é nesse movimento do cuidado que se possibilita a criação de um acesso que clareia o Ser. Clareia para o outro o que é a essência, se fazer vertente para o descobrimento, se colocar como vetor do desvelar. Ora,

O cuidado é indicado como "traço fundamental" da presença. Não se há de entender o cuidado, porém, como uma característica ou uma propriedade ôntica de um ente que ocorre aí ("presença" como ocorrência). O traço resulta de um traçar. O traçar,

\footnotetext{
${ }^{10}$ A palavra em alemão Sorge, utilizado por Heidegger em seus textos é ora traduzida para o português como cuidado, ora traduzida como cura. Para o autor, "a cura é sempre ocupação e preocupação, mesmo que de modo privativo" (HEIDEGGER, 2015, p. 261)
} 
contudo, se cumpre num imaginar. O humano como presença é uma imaginação (Heidegger, 1994b, p. 312). Contudo, essa imaginação não é nem empírica nem transcendental. É, antes, existencial ontológica. Este imaginar tem o sentido de trazer à luz o que vigora como poder-ser. Significa intuir no porvir outra possibilidade de configuração do humano e de o humano ser o que ele é, ou seja, configurador do mundo. Trata-se, portanto, de criar, a partir do poder-ser, outra forma de essencializarse do humano, na qual a humanidade do homem não se encontre fechada, mas aberta para o mistério de ser. Imaginação tem o sentido, aqui, de projeção da fundação da presença em seu poder-ser fundamental, como clareira do ser. $\mathrm{Na}$ ontologia fundamental, o cuidado aparece como uma totalidade estrutural (Heidegger, 1988, p. 255). Estrutural é aquela totalidade em que o todo se encontra todo em cada um de seus momentos. Isso quer dizer: totalidade não é, aqui, soma de partes, pois a presença não é nenhuma ocorrência (coisa ou "substância"); também não é sistema, pois a presença não é um ente que ocorre a modo do ser funcional (mecânico ou orgânico, causal eficiente ou causal-teleológico). Estrutural é uma totalidade existencial, isto é, uma totalidade que tem o modo de ser da liberdade. Isto quer dizer que as estruturas do cuidado são estruturações da liberdade. (FERNANDES, 2011, p. 162)

Deste modo, sigo aqui com a ideia do cuidado em Heidegger, e reflito que o cuidar heideggeriano é mais do que aquilo que temos como ato de cuidar, comumente. O cuidado ontológico - "é entender autenticamente o que é importante” (CARRARO, OLIVEIRA, 2010, p. 378). Pois, esse cuidar ontológico que compreende, como já disse anteriormente, é ser clareira para o outro que conosco co-habita.

Vejamos, se o estar no mundo é se relacionar com os entes que nele habitam, concluo, então, que a ética do cuidado é a ética de cuidar de si e dos outros em um movimento de ser-nomundo e de ser junto a. O cuidado do outro e o cuidado de si são, assim, as bases para as interrelações. A ética do cuidado é, provavelmente, a única ética que Heidegger esboçou e está intimamente conectada ao Dasein, ao estar-no-mundo.

Feito este adendo, voltamos à pergunta que provocou o início deste tópico. Não pretendo esgotar o tema, tampouco acredito que a resposta seja simples e certeira. Porém, para fins didáticos, digo: sim, é necessária a (des)construção - o prefixo entre parênteses me serve para demonstrar que a desconstrução precede imperativamente a construção, e que aqui o que propõe-se não é uma apenas uma ressignificação, mas uma nova compreensão construída através do movimento de desconstrução - sistêmica anti sistêmica do Direito. Sistêmica pois é preciso que essa desconstrução ocorra de forma pensada, reflexiva, dolosa, dolorosa. Anti sistêmica pois, uma vez realizado esse movimento de desconstrução que necessariamente dá lugar a uma abertura para o espiral hermenêutico dentro daquilo que conhecemos como Direito, o próprio conceito de Direito positivista não se sustentaria. Alguns são os pontos pelos quais pode-se perpassar para entender a queda da ideia positivista do Direito como ciência pura. 
Destarte, esse argumento resta escorado na dependência suicidária do Direito como ciência de conceitos fechados que são delimitadores porém delimitantes (em um sentido pejorativo). A tentativa kelseniana de transformar o Direito em algo científico e explicativo coloca o ser humano - como aquele que produz a norma - em uma posição de senhorio em relação às palavras. Os conceitos fecham-se e servem ao "operador" do Direito que, de forma mecânica (como os movimentos repetitivos do cego em meio à sua própria escuridão), aplica aquilo que é posto de forma positiva. Essa operação inteligente é também uma operação que coloca o racional como ponto de contradição à potencialidade de abertura que se faz possível no movimento da hermenêutica. Os conceitos tendem, então, a serem apreendidos por aqueles que dizem pensar e aplicar o Direito. Engessados, os conceitos param no tempo-espaço e estagnam a pragmática jurídica. Os juristas realizam esse exercício cego e estanque (como a ação de mascar o chiclete praticada pelo cego do conto de Clarice) pois pretendem

[...] uma apreensão ou domínio do real. Nesse sentido, Heidegger chega a se valer de uma exploração etimológica do vocábulo Begriffe, que em alemão significa conceito (Heidegger, 2008). Conforme sugere o pensador da Floresta Negra, esse vocábulo tem um campo semântico diretamente ligado ao verbo Greiffen, que, por sua vez, significa agarrar. Em outras palavras, a noção de conceito já estaria intrinsecamente ligada a uma noção de "agarramento" ou domínio. Ou, aproximando-nos novamente do texto derridiano, a uma pretensão de "tudo dizer" (tomado como to say everything). Diferentemente, a poesia e a literatura são marcadas por uma linguagem que se expressa e tem pretensões muito diversas. A literatura não se reduz à relação lógica de sujeito-objeto-predicado. O escritor é capaz de dizer sem afirmar, e tanto mais se aproxima da verdade quanto menos tem a pretensão de sustentá-la. Suas construções, por não trazerem pretensões veritativas, passam a incluir também o lado oculto e diversificado de seus entes. Ora, é por esse ocultamento que se permite o desvelar. Ao contrário do conceito, de que se valem a técnica e a ciência, a literatura ilumina sem ofuscar e permite que o ente se manifeste numa pluralidade infinita de sentidos. Assim, a partir de suas leituras de Hölderlin, Heidegger apresenta uma nova possibilidade de pensamento que se aproxima do poético. A linguagem da poesia é pensada como uma nova possibilidade de atitude existencial humana que extrapola as significações habituais: "poesia é o deixar habitar em sentido próprio" (Heidegger, 2003, p. 167). (RIBEIRO, 2019, pp. 468-469)

Explico que a hermenêutica funciona no sentido de mostrar a dualidade e a inesgotabilidade das palavras. A ciência - e falo também aqui do Direito como ciência, já que tem pretensão de pureza - cai em uma aporia, ou seja, em uma ilusão de domínio da linguagem e dos conceitos que através dela se expressam. Esse exercício científico de apreensão de conceitos se torna por vezes uma chancela autoritativa do conhecimento que, por sua vez, se apresenta como força dogmática. Nessa tentativa de se agarrar ao conceito o cientista aumenta as suas chances de velar o seu real sentido. 
Em movimento contrário, o hermeneuta desvela a possibilidade do espanto no caráter inesgotável das palavras. Enquanto as ciências duras preferem a explicação, as ciências humanas preferem a compreensão. Compreender depende do espanto. O espanto é algo que provoca - algo sobre o qual falei em momento anterior, ao citar o texto de Clarice $-\mathrm{e}$ se encontra consequentemente na linguagem, que é o que realmente diz. Nessa mesma linha, o poeta se aproxima das coisas sem a pretensão de domínio que cega o cientista. Assim, o poeta se aproxima mais dos conceitos - e do Ser - do que qualquer cientista. Se opera, então, a manutenção do espanto permanente. Sobre o tema, Heidegger pontua que

\begin{abstract}
Mas aonde nós, os humanos, podemos nos informar sobre a essência do habitar e da poesia? Aonde o homem assume a exigência de adentrar a essência de alguma coisa? $\mathrm{O}$ homem só pode assumir essa exigência a partir de onde ele a recebe. Ele a recebe no apelo da linguagem. Mas isso, certamente, apenas e enquanto o homem já estiver atento à essência da linguagem. Todavia, circula no planeta, de maneira desenfreada e hábil, um falatório, um escrever e uma transmissão de coisas ditas. O homem se comporta como se fosse o criador e o soberano da linguagem. A linguagem, no entanto, permanece a soberana do homem. Quando essa relação de soberania se inverte, o homem decai numa estranha mania de produção. A linguagem torna-se meio de expressão. Enquanto expressão, a linguagem pode apenas ser rebaixada a simples meio de pressão. Cuidar do dizer, mesmo nessa manipulação da linguagem, é, sem dúvida, positivo. Contudo, só esse cuidado não basta para nos ajudar a retornar à verdadeira relação de soberania entre a linguagem e o homem. Em sentido próprio, a linguagem é que fala. $\mathrm{O}$ homem fala apenas e somente à medida que corresponde à linguagem, à medida que escuta e pertence ao apelo da linguagem. (HEIDEGGER, 2012b, p. 167)
\end{abstract}

É imperativo, portanto, que habitemos poeticamente o mundo e tudo que nele se dá. O Direito, como fenômeno humano que é - não apenas porque é produzido de forma positiva pelo homem, mas também porque se dá no mundo do Dasein como construção daquilo que é relacional com o Outro - deve também ser habitação. Ao fazer do Direito habitação devolverse-á para a linguagem a sua posição de soberana. Aquilo que o Direito diz ser - o dogma, o conceito, a certeza - se desfaz na liquidez poética do habitar. O jurista, em uma ação hermenêutica, não estará mais preso aos discursos que já vem categorizados e às palavras que já vêm carregadas de auto evidência. O sentido predisposto de tudo aquilo que circunda a atividade jurídica é contestado pela abertura que a hermenêutica produz. Essa abertura é possível não porque a hermenêutica possibilita múltiplas formas de se entender uma norma positivada. Muito antes disso, a hermenêutica nos permite entender a partir da multiplicidade e da alteridade o que o Direito é/deve ser. O devir do Direito. Retornamos à linguagem a soberania sobre o homem, no Direito. 
Outro ponto importante do argumento pela desconstrução do Direito aqui apresentado está justamente no Direito entendido não como fato social mas como fenômeno humano (do ser humano). Expor a ideia de que a defesa do argumento pela desconstrução hermenêutica e anti sistêmica do Direito faz com que as teorias positivistas caiam significa dizer, invariavelmente, que pelo menos uma das principais teses positivistas não se sustentaria. Ora, se dizemos que o Direito é um fenômeno humano antes de ser um sistema de regras e princípios resultantes de uma convenção social, então a Tese dos Fatos Sociais - tão importante para as teorias positivistas - não mais seria. O revolver hermenêutico é inexoravelmente pré-predicativo. As reflexões que dele decorrem não formam apenas um campo de questionamentos sobre convenções sociais ou legitimidade da autoridade. O revolver que ocorre através da hermenêutica faz pensar o próprio Sein do Direito. Ou seja, nos faz pensar não apenas no que o Direito é, mas também no que o Direito deve ser, como uma unidade fenomenológica.

A conexão necessária que se faz através dessa operação é que aquilo que o Direito é e deve ser se dá, inexoravelmente, sob o signo de um agir ético do cuidado. A ética do cuidado é, aqui, também pré-predicativa. Pré-predicativa da existência do Direito, que só se concretiza como unidade do ser e dever ser quando já existe a ética na qual ele se baseia. Heidegger diz que

É possível que a poesia seja uma medida extraordinária. E ainda mais. Talvez a frase:
Ditar poeticamente é medir, deva se pronunciar com um outro acento: Ditar
poeticamente é medir. Na poesia, acontece com propriedade o que todo medir é no
fundo de sua essência. Por isso, cabe prestar atenção ao ato fundamental realizado
pelo medir. Medir consiste, sobretudo, em se conquistar a medida com a qual se há de
medir. Na poesia, acontece com propriedade a tomada de uma medida. No sentido
rigoroso da palavra, poesia é uma tomada de medida, somente pela qual o homem
recebe a medida para a vastidão de sua essência. O homem se essencializa como o
mortal. Assim se chama porque pode morrer. Poder morrer significa: ser capaz da
morte como morte. Somente o homem morre - e, na verdade, continuamente, enquanto
se demora sobre esta terra, enquanto habita. Seu habitar se sustenta, porém, no
poético. (HEIDEGGER, 2012b, p. 173)

O habitar poético - em uma ação de cuidar de si e o outro - se torna, através desse movimento hermenêutico de significação pré-predicativa, a medida do Direito. Se medimos o Direito por meio da poesia nos permitimos então uma abertura à linguagem e, assim, à essência. Se compreende desta forma o Direito em sua finalidade e em sua finitude: como fenômeno humano que é.

Quando habita-se poeticamente compreende-se que há algo para além - ou que predica aquilo que pensávamos. Por meio dessa nova experiência podemos ver também que existe algo 
que o Direito é e deve ser para além daquilo que se pensava. Podemos assim, possibilitar a abertura para aquilo que a linguagem quis dizer.

Não é, para isso, estritamente imperativo que se opere uma mudança na letra fria da Constituição, por exemplo. Tampouco pode-se imaginar que seria necessário - ou quiçá possível - operar alguma modificação nas circunstância históricas que outrora circundaram a elaboração do texto constitucional. O que muda é, antes de qualquer coisa, a maneira de se entender o Direito, de forma análoga à pausa no movimento mecânico da vida de Ana ao se deparar com o cego mascando chiclete. Quebram-se os ovos da lei para que assim se torne possível ver além, ver dentro. Ver e enxergar. Afinal, tanto Ana - que não enxerga o mundo ao seu redor - quanto o cego - que não tem a capacidade concreta da visão - nos servem para compreender que há sempre a possibilidade da poesia no habitar, ora,

E nós habitamos poeticamente? Parece que habitamos sem a menor poesia. Se é
assim, será mentirosa e não verdadeira a palavra do poeta? Não. A verdade de suas
palavras se confirma da maneira mais inacreditável. Pois um habitar só pode ser sem
poesia porque, em sua essência, o habitar é poético. Um homem só pode ser cego
porque, em sua essência, permanece um ser capaz de visão. [...] Se e quando uma
virada nesse habitar sem poesia há de acontecer, isso só devemos esperar prestando
atenção ao poético. Como e em que extensão nosso fazer e nosso deixar de fazer são
partes ativas dessa virada, isso só podemos garantir levando a sério o poético. A
poesia é a capacidade fundamental do modo humano de habitar. (HEIDEGGER,
2012b, p. 179)

A hermenêutica traça esse caminho entre o habitar sem poesia e o habitar com poesia, para o Direito. O habitar poético deve estar, então, na própria busca pelo conceito do Direito conceito esse que visa a compreensão e não a apreensão - indo, assim, além do que é qualificatório, classificatório ou descritivo. A ciência do Direito, que se apresenta por vezes como dogma, está em um ponto oposto ao da filosofia como arte de questionar - locus no qual é permitido a elaboração de uma pergunta chave que não enseja uma resposta pronta imediata. Para Heidegger "a filosofia é uma ontologia fenomenológica e universal que parte da hermenêutica da presença, a qual, enquanto analítica da existência, amarra o fio de todo o questionamento filosófico no lugar de onde ele brota e para onde ele retorna" (HEIDEGGER, 2015, p. 78)

Desprender-se de obviedades já cientificamente chanceladas é possível e necessário pois esse mesmo habitar poético que se dará no próprio conceito do Direito dá ensejo à abertura da linguagem que permeia o exercício de interpretação das normas. Como já dito em alhures, a 
norma posta - positivada - é a mesma, mas pode haver um revolver na interpretação porque a partir daí algo transcende o abstracionismo interpretativo e vai para algo mais concreto.

Caminho para o encerramento deste texto argumentando que o existir no mundo é estar aberto aos afectos. Se compreendemos e existimos no mundo, se nele habitamos poeticamente, apreendemos a nossa realidade de modo diverso, menos simplório, ontológico. Dessa forma parafraseando Jacques Derrida - se há existência, há desconstrução. Assim, não podemos esperar que sob uma ótica do cuidado e pelo caminho da hermenêutica a vivência do Direito continue ocorrendo dentro do sistema que hoje conhecemos. Porque habitar o mundo poeticamente implica enxergar por uma outra lente a nossa presença. Essa lente, como um caleidoscópio, movimenta de forma a desvelar o que antes era apenas repetição no escuro (como as ações do cego no conto de Clarice).

Por fim: o (des)construir do Direito é o que manterá o aberto ao espanto e à compreensão.

\section{CONCLUSÃO}

Se existe qualquer pretensão de que Martin Heidegger sirva como ponto de partida para uma guinada poético-hermenêutica do Direito, é preciso entender que sua fenomenologia deve ir além de um simples exercício de interpretação atenta à autoridade. O hermeneuta deve revolver uma naturalização das coisas.

Aqui, o que deve-se operacionalizar é o que coloquei como reflexão pré-predicativa, quase que como um meio heideggeriano de sich-vorweg-im-schon-sein-in-einer-Weld ou anteceder-a-si-mesma-no-já-ser-em-um-mundo (HEIDEGGER, 2015, p, 587). É por meio desse movimento reflexivo que se dá antes mesmo da construção de um conceito daquilo que é o Direito que se torna possível o perfazimento do Direito como fenômeno humano (antes mesmo de ser social) que, por sua vez, enseja o cumprimento daquilo é a sua própria raison d'être ontológica e heideggeriana.

\section{REFERÊNCIAS BIBLIOGRÁFICAS}

CARRARO, Telma Elisa; OLIVEIRA, Marília de Fátima Vieira de. Cuidado em Heidegger: uma possibilidade ontológica para a enfermagem. Rev Bras Enferm, Brasília 2011 mar-abr; 
64 (2): $\quad$-abr; $64(2): \quad$ 376-80. $\quad$ Disponível <https://www.scielo.br/pdf/reben/v64n2/a25v64n2.pdf> Acesso em: 27 de ago. de 2020.

DAHAS, Débora Caetano. Amor ao mar (e outros escritos). $1^{\mathrm{a}}$ ed. Lisboa: Chiado Books, 2019.

FERNANDES, Marco Aurélio. O cuidado como amor em Heidegger. Rev. abordagem gestalt. vol.17 no.2 Goiânia dez. 2011. Disponível em: <http://pepsic.bvsalud.org/scielo.php?script=sci_arttext\&pid=S1809-68672011000200007>

Acesso em: 27 de ago. de 2020.

HEIDEGGER, Martin. A caminho da linguagem. Tradução de Emmanuel Carneiro Leão, Gilvan Foge, Marcia Sá Cavalcante Schuback. - 8. ed. - Petrópolis: Vozes; Bragança Paulista: Editora Universitária São Francisco, 2012a.

. “...Poeticamente o homem habita..." IN.: Ensaios e Conferências. Tradução de Emmanuel Carneiro Leão, Gilvan Foge, Marcia Sá Cavalcante Schuback. - 8. ed. - Petrópolis: Vozes; Bragança Paulista: Editora Universitária São Francisco, 2012 b.

Ser e tempo. Tradução revisada e apresentação de Marcia Sá Cavalcante Schuback. Posfácio de Emmanuel Carneiro Leão. Petrópolis: Vozes. Bragança Paulista: Editora Universitária São Francisco, 2015.

KELSEN, Hans. Teoria Pura do Direito. São Paulo. Martins Fontes, 2009.

LISPECTOR, Clarice. Amor. IN.: Todos os Contos. Organizado por Benjamin Moser. Rocco, 2015.

RIBEIRO, Fernando Armando. Essa estranha instituição chamada literatura e o direito. ANAMORPHOSIS - REVISTA INTERNACIONAL DE DIREITO E LITERATURA, v. 5, p. 465-489-489, 2019. Disponível em 〈http://rdl.org.br/seer/index.php/anamps/article/view/487> Acesso em: 27 de ago. de 2020.

SANTOS, Eder Soares. Em busca de uma ética do cuidado à luz de Heidegger, Nishitani e Winnicott. Winnicott e-prints, vol. 6, no. 1, São Paulo, 2011. Disponível em $<$ http://pepsic.bvsalud.org/pdf/wep/v6n1/a03.pdf> Acesso em: 27 de ago. de 2020.

SCHUBAK, Marcia Sá Cavalcante. A perplexidade da presença. IN.: Ser e tempo. Tradução revisada e apresentação de Marcia Sá Cavalcante Schuback. Posfácio de Emmanuel Carneiro Leão. Petrópolis: Vozes. Bragança Paulista: Editora Universitária São Francisco, 2015.

Rev. de Argumentação e Hermenêutica Jurídica | e-ISSN: 2526-0103 | Encontro Virtual | v. 6 | n. 2 |

p. 21 - 40 | Jul/Dez. 2020. 
Trivisonno, Alexandre T. G. O que Significa "A Injustiça Extrema não é Direito"? Crítica e Reconstrução do Argumento da Injustiça no Não-Positivismo Inclusivo de Robert Alexy. EJJL, Joaçaba, v. 16, n. 3, p. 97-122, Edição Especial, 2015. Disponível em <https://unoesc.emnuvens.com.br/espacojuridico/article/view/9676> Acesso em: 27 de ago. de 2020. 